\title{
Contributions of poroelastic rebound and a weak volcanic arc to the postseismic deformation of the 2011 Tohoku earthquake
}

\author{
Yan Hu*, Roland Bürgmann', Jeffrey T Freymueller ${ }^{2}$, Paramesh Banerjee ${ }^{3}$ and Kelin Wang ${ }^{4}$
}

\begin{abstract}
A better understanding of fluid-related processes such as poroelastic rebound of the upper crust and weakening of the lower crust beneath the volcanic arc helps better understand and correctly interpret the heterogeneity of postseismic deformation following great subduction zone earthquakes. The postseismic deformation following the $2011 M_{w} 9.0$ Tohoku earthquake, recorded with unprecedented high resolution in space and time, provides a unique opportunity to study these 'second-order' subduction zone processes. We use a three-dimensional viscoelastic finite element model to study the effects of fluid-related processes on the postseismic deformation. A poroelastic rebound (PE) model alone with fluid flow in response to coseismic pressure changes down to 6 and $16 \mathrm{~km}$ in the continental and oceanic crusts, respectively, predicts 0 to $6 \mathrm{~cm}$ uplift on land, up to approximately $20 \mathrm{~cm}$ uplift above the peak rupture area, and up to approximately $15 \mathrm{~cm}$ subsidence elsewhere offshore. PE produces up to approximately $30 \mathrm{~cm}$ of horizontal motions in the rupture area but less than $2 \mathrm{~cm}$ horizontal displacements on land. Effects of a weak zone beneath the arc depend on its plan-view width and vertical viscosity profile. Our preferred model of the weak sub-arc zone indicates that in the first 2 years after the 2011 earthquake, the weak zone contributes to the surface deformation on land on the order of up to $20 \mathrm{~cm}$ in both horizontal and vertical directions. The weak-zone model helps eliminate the remaining systematic misfit of the viscoelastic model of upper mantle relaxation and afterslip of the megathrust.
\end{abstract}

Keywords: Poroelastic rebound; Weakened lower crust beneath the arc; Giant earthquake; Subduction zone; Viscoelastic postseismic deformation; Finite element model; Numerical simulation

\section{Background}

Geodetic observations of deformation before, during, and after $M \sim 9$ megathrust earthquakes illuminate the mechanics and rheology of the subduction zone system. Wang et al. (2012) summarized three primary subduction processes that dominate earthquake cycle deformation following a great megathrust earthquake: aseismic afterslip on the subduction thrust, viscoelastic relaxation of the upper mantle, and re-locking of the fault. Immediately after the earthquake, afterslip on the subduction megathrust and a transient viscoelastic response of the mantle result in rapidly decaying trench-ward surface displacements (e.g., Pollitz et al., 2008; Ozawa et al., 2012;

\footnotetext{
* Correspondence: yhu@seismo.berkeley.edu

'Berkeley Seismological Laboratory and Department of Earth and Planetary Science, University of California Berkeley, 307 McCone Hall, Berkeley, CA 94720, USA

Full list of author information is available at the end of the article
}

Lin et al. 2013). Decades after the earthquake, the coastal area moves towards the land due to the re-locking of the fault, while viscoelastic relaxation of the mantle still causes prolonged seaward motions in the inland area (e.g., $\mathrm{Hu}$ et al., 2004; Wang et al., 2003, 2007; Suito and Freymueller, 2009; Hu and Wang, 2012). Later in the earthquake cycle (e.g., McCaffrey et al., 2013), the earthquake-induced stresses in the mantle are mostly relaxed, and the effects of the re-locking of the fault dominate leading to a landward displacement gradient consistent with elastic deformation about the subduction thrust coupled in the upper approximately $50 \mathrm{~km}$ of the lithosphere (Savage, 1983). The recent devastating $M \sim 9$ megathrust earthquakes in Sumatra, Chile, and Japan provide unique opportunities to improve our understanding of the subduction earthquake cycle through observations of the deformation with modern space-geodetic techniques.

\section{然}

(c) 2014 Hu et al.; licensee Springer. This is an Open Access article distributed under the terms of the Creative Commons Attribution License (http./creativecommons.org/licenses/by/40), which permits unrestricted use distribution, and reproduction in any medium, provided the original work is properly credited. 
Here we focus on modeling the postseismic deformation following the 11 March $2011 M_{w} 9.0$ Tohoku earthquake in NE Japan (Pollitz et al., 2011; Ozawa et al., 2012; Iinuma et al., 2012), exploring the role of fluids in earthquake cycle deformation. Specifically, we consider (1) the contribution of fluid flow in response to coseismic pressure changes in the lithosphere to the postseismic deformation and (2) the role of fluids rising from the subducting slab in the volcanic arc of NE Japan in producing localized weakening of the lower crust.

Tens of meters of instantaneous coseismic slip of the fault cause sudden pressure changes in the surrounding rocks. Pore fluid pressure immediately increases in the compressional areas and decreases in dilatational areas in the initial undrained condition. After the earthquake, fluids will migrate from high-pressure areas to lowpressure areas resulting in time-dependent surface deformation associated with poroelastic rebound (Peltzer et al., 1996, 1998). Migration of fluids thus causes the pore fluid pressure to evolve towards an equilibrium condition in which the earthquake-induced fluid flow has completed, commonly referred to as 'drained' condition. This time-dependent process (e.g., Jónsson et al., 2003; Masterlark, 2003) is controlled by the variable viscosities of fluids, the rock properties, and the complex permeability structure of the lithosphere. A common way to predict the deformation resulting from the completed poroelastic rebound is to consider only the difference in elastic coseismic deformation between the undrained condition immediately after the earthquake and the fully relaxed equilibrium condition long after the earthquake (e.g., Masterlark, 2003; Jónsson et al., 2003). This is accomplished by differencing coseismic deformation models in which portions of the lithosphere where earthquake-induced fluid flow is believed to occur are modeled with undrained and equilibrium values of Poisson's ratio. Study of poroelastic rebound helps to better understand the contributions of fluidflow processes in shaping the transient stress field and evolving earthquake hazard (e.g., Peltzer et al., 1998; Hughes et al., 2010) and to gain insights on the permeability/porosity structure of and fluid flow in subduction zone systems (e.g., Nur and Walder 1990).

The poroelastic rebound model has been applied to study crustal deformation associated with subduction zone earthquakes such as the 2004 $M_{w} 9.2$ Sumatra (Hughes et al., 2010) and $1980 M_{w} 8.0$ Jalisco-Colima, Mexico, earthquakes (Masterlark, 2003). Hughes et al. (2010) presented a finite element model of the poroelastic rebound following the 2004 Sumatra earthquake that produced up to a few tens of centimeters of horizontal displacements near the trench and less than $30 \mathrm{~cm}$ uplift in the vicinity of the rupture zone. Masterlark (2003) suggests that a model with bulk permeability of the oceanic crust less than $10^{-17} \mathrm{~m}^{2}$ may explain the quasistatic coupling of an earthquake swarm that has a 63-day lag time following the $1980 M_{w} 8.0$ Jalisco-Colima earthquake. However, the contribution of poroelastic rebound to the postseismic deformation of the 2011 Tohoku earthquake has yet to be investigated (Ozawa et al., 2012; Johnson et al., 2012; Diao et al., 2014).

It is also known that compaction and heating of the hydrated subduction slab results in fluids migrating into the overlying mantle wedge (Manning, 2004). These fluids weaken the overriding plate and may cause partial melting (e.g., Saffer and Bekins, 1999; van Keken et al., 2002). Through modeling heat flow, seismic tomography, and magnetotelluric data, Muto (2011) and Muto et al. (2013) have proposed that viscosities of the lower crust below the arc in NE Japan are several orders of magnitude lower than in the surrounding crust. After examining interseismic strain anomalies and the coseismic deformation of the 2011 earthquake in NE Japan, Ohzono et al. (2012b) proposed a weak zone below the tens of kilometers wide Ou-backbone range, in the vicinity of the arc. A low-viscosity lower crust (2 to $5 \times$ $10^{18} \mathrm{~Pa} \mathrm{~s}$ ) at depths $>20 \mathrm{~km}$ is also indicated by the postseismic relaxation of the 2008 Iwate-Miyagi Nairiku earthquake located in the arc (Ohzono et al., 2012a).

Postseismic deformation following the $2011 M_{w} 9.0$ Tohoku earthquake has been recorded at more than 1,200 continuous land Global Positioning System (GPS) stations (Ozawa et al., 2012) as well as a few marineacoustic campaign GPS stations (Sato et al., 2013; Kido et al., 2013; Japan Coast Guard and Tohoku University 2013; Watanabe et al. 2014) at unprecedented high spatial and temporal resolutions. The 2011 earthquake thus provides a unique opportunity to study processes other than the three primary deformation processes mentioned above, illuminating the role of fluids and material heterogeneity in the postseismic deformation. We believe that it is important to understand the possible contributions of these higher-order effects to the postseismic deformation field as they will impact any postseismic deformation models which parameterize structure and properties of the Earth through comparing with observations. In this paper, we present a three-dimensional (3D) viscoelastic finite element model to illuminate the effects of the poroelastic rebound in the crust and the rheology heterogeneity below the arc.

\section{Methods}

\section{Geodetic observations and postseismic displacement} estimates

Postseismic displacements at geodetic stations are estimated based on the land GPS observations and seafloor GPS-acoustic (GPS-A) measurements (Figure 1). We obtained daily time series of more than 1,200 continuous 


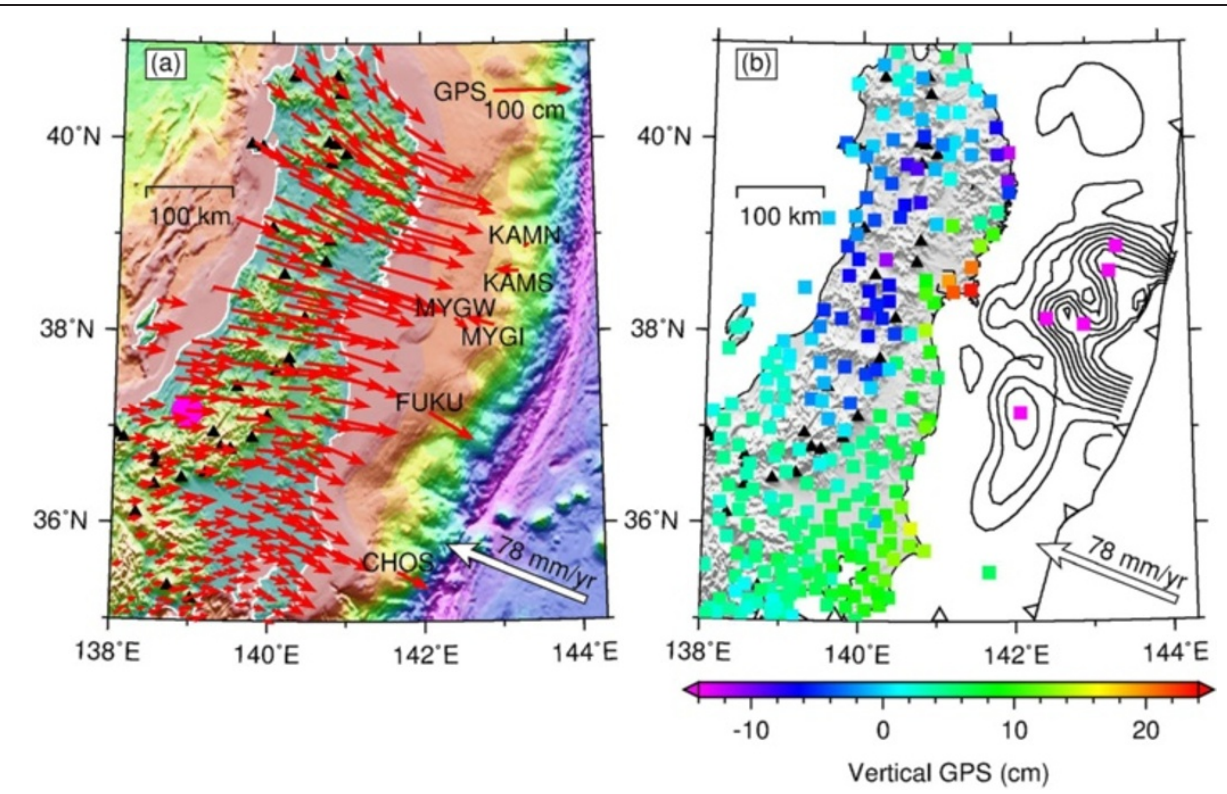

Figure 1 Tectonic setting and postseismic GPS observations in NE Japan. (a) Horizontal displacements. Red arrows represent 2-year GPS observations since the 2011 Tohoku earthquake. The solid magenta circle represents the location of the example GPS station whose time series is presented in Additional file 1: Figure S1. Solid black triangles represent active volcanoes. (b) Vertical displacements of GPS stations 2 years after the 2011 earthquake. Black contours at 5-meter intervals show the coseismic slip distribution from linuma et al. (2012).

GPS stations (GEONET) processed in ITRF2008 (Altamimi et al., 2011) by the Geospatial Information Authority of Japan (GSI) (Miyazaki et al. 1998). The GPS time series span from as early as 1996 to March 2013. The GPS time series represent a combined signal of non-tectonic seasonal deformation, interseismic locking, and postseismic processes. In this work, we are interested in deformation only due to postseismic processes.

Estimates of the postseismic deformation directly from the daily GPS time series suffer from the epoch noise level. We take the following steps to estimate the total postseismic displacements over a 2-year period (from 12 March 2011 to 30 March 2013). This approach is thus not comprised by any data gaps or problems at the time exactly 2 years after the earthquake. First, we select an interseismic time window in which previous earthquakes have minimum contributions to surface deformation. A function consisting of a linear trend and seasonal sinusoidal terms is fitted to the interseismic time series to approximate the pre-earthquake trends to account for non-tectonic seasonal deformation and the interseismic locking (Additional file 1: Figure S1). We subtract the pre-earthquake motions from the postseismic time series to estimate postseismic displacements only due to the earthquake-related processes that are examined in this work. We fit a parametric model to the time series and evaluated the model to provide displacements over desired time windows. Finally, displacements at all stations are referenced to station FUKUE (station ID 950462) such that displacements at these stations are comparable to model-predicted results that are with respect to the fixed upper plate. For details of processing of the GPS time series, please see Additional file 1: Section 1.

Land GPS stations recorded up to approximately $1 \mathrm{~m}$ horizontal and approximately $1.2 \mathrm{~m}$ vertical postseismic displacement within 2 years after the 2011 earthquake (Figure 1). All the GPS stations move in roughly the same seaward direction as during the coseismic rupture (Figure 1a). Two years after the earthquake, the eastern coastal stations landward of the rupture zone feature up to approximately $20 \mathrm{~cm}$ uplift while areas farther inland and north experienced up to approximately $15 \mathrm{~cm}$ subsidence (Figure 1b).

In addition to the GEONET data, we also consider 2-year postseismic displacements at six GPS-A stations that were repeatedly surveyed by the Japanese Coast Guard, starting 2 to 4 weeks after the earthquake (Japan Coast Guard 2012; Japan Coast Guard and Tohoku University 2013; Watanabe et al. 2014) (Figure 1). The GPS-A station displacements are also relative to station FUKUE. The elastic strain associated with subduction of the Pacific plate at a rate of approximately $8 \mathrm{~cm} /$ year (e.g., Sella et al., 2002; Apel et al., 2006) makes a modest contribution to the large postseismic displacements at these sites (Sato et al., 2013). Because of the campaign-mode observations of the GPS-A stations, we do not take the same steps as in processing the daily time series of the GEONET stations (Additional file 1: Section 1). Effects of interseismic locking are accounted for by removing the interseismic velocities of those marine stations reported by Sato et al. (2013) from the postseismic 
displacements. Figure 1 shows displacements of these GPSA stations only due to postseismic processes. Figure 1a illustrates that MYGI and KAMS have moved landward while the other stations are moving seaward. Except for station CHOS that exhibits insignificant vertical deformation, all the other offshore stations underwent subsidence of approximately 10 to $40 \mathrm{~cm}$ in the first 2 years after the 2011 earthquake (Japan Coast Guard and Tohoku University 2013). At FUKU and MYGW, more than 50\% of the 2 -year subsidence took place in the first 6 months, while stations KAMN, KAMS, and MYGI experienced a more gradual decay of the subsidence rate.

\section{Finite element model}

The finite element model used in this work is based on previous mechanical models developed to study the postseismic and interseismic deformations of the Sumatra, Chile, and Cascadia margins (Hu et al., 2004; Wang et al., 2012; Hu and Wang, 2012). The finite element model includes an elastic 40-km-thick upper continental plate, an elastic $80-\mathrm{km}$-thick subducting slab, and viscoelastic continental and oceanic upper mantles (Figure 2a). Poroelastic rebound in the shallow crust and a weak volcanic arc (gray-shaded areas in Figure 2a) will be investigated in the 'Poroelastic rebound in the crust' and 'Weakened zone beneath volcanic arc' sections, respectively. The bottom of the model is at $500-\mathrm{km}$ depth in the transition zone. Lateral model boundaries are set to be at least $1,000 \mathrm{~km}$ from the rupture zone. Deformation at the model boundaries, except at the free upper surface, is free in the tangential directions and fixed in the normal direction. The bi-viscous Burgers rheology, incorporating a transiently relaxing Kelvin solid and steady-state Maxwell fluid, is assumed to represent the constitutive properties of the viscoelastic upper mantle (Bürgmann and Dresen, 2008). Coseismic slip (Iinuma et al., 2012) (Figure 2c) is modeled as sudden forward slip of the megathrust through the split-node method (Melosh and
Raefsky, 1981). Note that details of the coseismic source model are not important for the far-field deformation, and different source models yield approximately the same postseismic viscoelastic deformation at the land GPS stations. Time-dependent, stress-driven afterslip away from the rupture zone is modeled through a 2-km-thick weak shear zone attached to the megathrust (brown and green layers in Figure 2a). The viscosity of the shallow shear zone $(\leq 50 \mathrm{~km}$, brown layer in Figure $2 \mathrm{a})$ is one order of magnitude lower than that of the deep shear zone (50 to $120 \mathrm{~km}$, green layer in Figure 2a) to produce more afterslips at shallow depths as indicated by observed aftershocks and repeating earthquakes (Uchida and Matsuzawa, 2013).

This paper focuses on the effects of fluid-related processes during the early postseismic relaxation. First, we present the results of a reference model (REF) with fixed viscoelastic parameters that were based on previous studies (e.g., Hu et al., 2004; Hu and Wang, 2012; Wang et al., 2012) and were found to provide a good firstorder fit to the early postseismic deformation. Then we evaluate the impacts of poroelasticity and mantle heterogeneity in the arc center. In REF, the shear moduli for the elastic plates and viscoelastic upper mantle are assumed to be 48 and $64 \mathrm{GPa}$, respectively. Poisson's ratio and rock density are assumed to be 0.25 and $3.3 \mathrm{~g} / \mathrm{cm}^{3}$, respectively, for the entire domain. The Maxwell steadystate viscosity $\eta_{\mathrm{M}}$ of the mantle wedge and oceanic mantle is $10^{19}$ and $10^{20} \mathrm{~Pa} \mathrm{~s}$, respectively. $\eta_{\mathrm{M}}$ of the shallow $(\leq 50 \mathrm{~km})$ and deep (50 to $120 \mathrm{~km})$ afterslip shear zones are $10^{17}$ and $10^{18} \mathrm{~Pa} \mathrm{~s}$, respectively. The Kelvin transient viscosity $\eta_{\mathrm{K}}$ of the Burgers body in the reference and all the following test models is assumed to be one order of magnitude lower than $\eta_{\mathrm{M}}$. Details of the reference model and a thorough exploration of the model parameter space will be published elsewhere $(\mathrm{Hu}$ et al., manuscript in preparation).

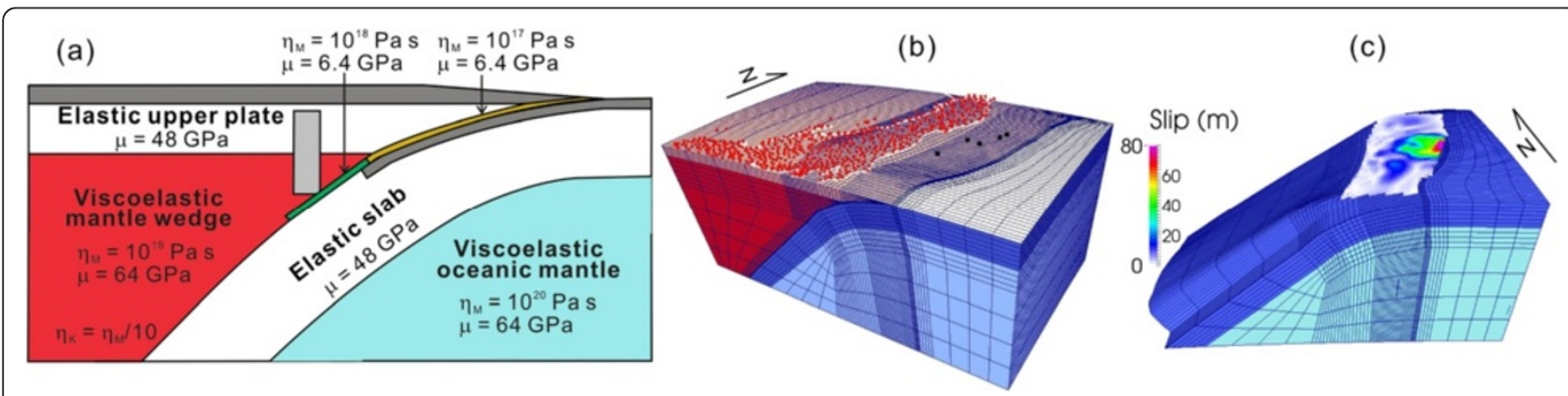

Figure 2 Conceptual model parameterization and finite element mesh. (a) The finite element model. Dark and light gray-shaded regions represent the poroelastic layers and the weak volcanic arc that are considered in the 'Poroelastic rebound in the crust' and 'Weakened zone beneath volcanic arc' sections, respectively. $\mu, \eta_{M}$, and $\eta_{K}$ are shear modulus, steady-state Maxwell viscosity, and transient Kelvin viscosity, respectively. (b) Central part of the finite element mesh. Red and black dots represent locations of the land and marine GPS stations, respectively. Thick white lines represent coast lines. (c) Central part of the finite element mesh with the upper plate removed. Color contours are the coseismic slip distribution (linuma et al., 2012). 
Following the approach of developing the FEM mesh in $\mathrm{Hu}$ and Wang (2012), we manually derived 32 latitudeparallel profiles based on published slab geometry data (Nakajima and Hasegawa, 2006; Zhao et al., 2009), relocated seismicity (Engdahl et al., 1998), and locations of the trench (Bird, 2003) and the arc. Our slab geometry is similar to that used in Iinuma et al. (2012). These latitude-parallel profiles were then used to construct the finite element mesh. It consists of 147,867 nodal points in 17,408 27-node quadratic elements. The element size is on the order of $100 \mathrm{~m}$ near the fault and up to $500 \mathrm{~km}$ farther away. The central part of the mesh is shown in Figure 2b. The parallel modeling finite element code PGCvesph was developed at the Pacific Geoscience Centre, Geological Survey of Canada (e.g., Hu and Wang, 2012; Wang et al., 2012).

\section{Results and discussion}

A comparison of the GPS observations with the REF model displacements is presented in Figure 3. REF predicted 2-year displacements fit the first-order pattern of the seaward motion of the land GPS stations (Figure 3a). The systematic misfit of horizontal displacements south of $37^{\circ} \mathrm{N}$ and along the coast near $40^{\circ} \mathrm{N}$ may be due to local processes such as aftershocks in this region. The subduction of the Philippine Sea plate that is not considered in this work may also contribute to the misfit in the south. In the vertical component, REF successfully predicts uplift along the eastern coast behind the rupture zone and subsidence further inland (Figure 3b). REF produces approximately $10 \mathrm{~cm}$ subsidence at stations
KAMN, KAMS, and MYGI, a pattern consistent with GPS-A observations (Watanabe et al. 2014). At MYGW and CHOS, REF underestimates the observed vertical motion. At FUKU, the vertical motion predicted by REF is contrary to the observation. Horizontal displacements produced by REF are overall consistent with these of GPS-A stations except the directions of KAMS and MYGI.

Below we explore a series of forward models of (1) the poroelastic rebound of the continental and oceanic crusts and (2) the viscous relaxation of a localized, fluidweakened zone below the NE Japan volcanic arc and explain how deformation from these processes affects the fit of REF to the GPS observations. Through these models, we aim to better understand the uncertainties of the model parameters and the role of fluid-mediated processes in the postseismic deformation.

\section{Poroelastic rebound in the crust}

In this section, we present test models of poroelastic rebound (PE) in the continental and oceanic crusts. Laboratory and geologic studies indicate that crustal permeability decreases rapidly below about 4-km depth (Manning and Ingebritsen, 1999). Based on geothermal models and properties of metamorphic rocks, Manning and Ingebritsen (1999) reported that the permeability in the upper $15 \mathrm{~km}$ of the crust decreases logarithmically with a depth from $10^{-14}$ to $10^{-18} \mathrm{~m}^{2}$. Masterlark (2003) proposed that a model with a permeability of the oceanic crust $10^{-17} \mathrm{~m}^{2}$ well explained the 63-day lag time of an earthquake swarm following the $1995 M_{w} 8.0$ Jalisco-Colima mainshock, which is consistent

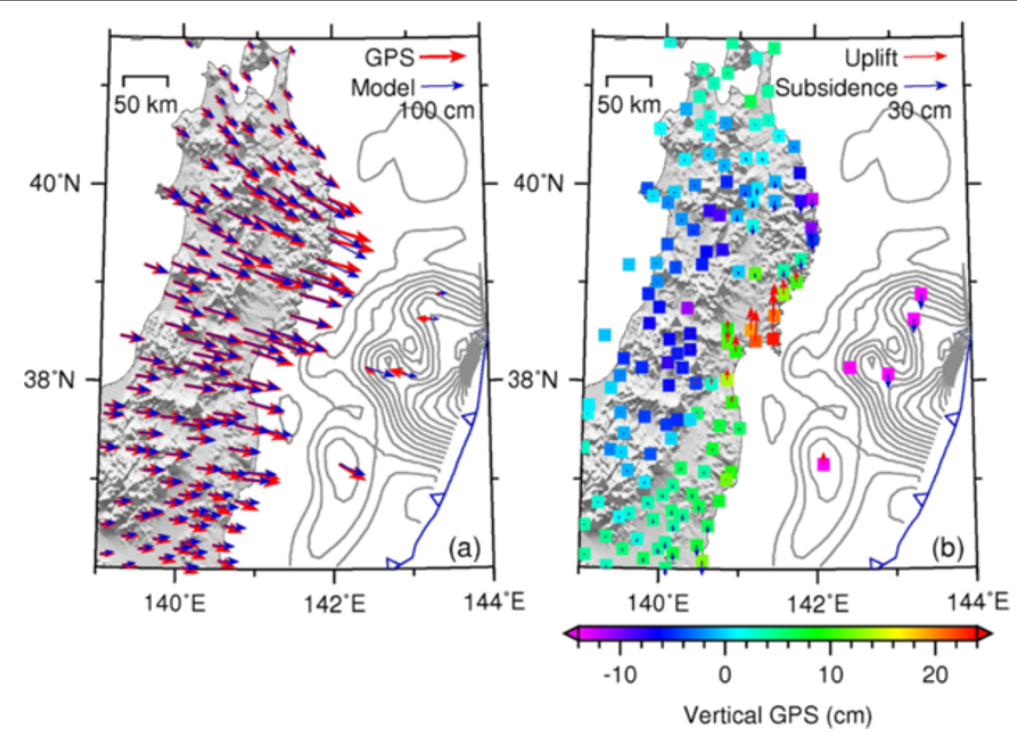

Figure 3 Comparison of GPS observations with reference model-predicted displacements. (a) Horizontal displacements. Red arrows represent 2-year GPS displacements since the 2011 earthquake. Blue arrows are model-predicted displacements. Contours are the same coseismic slip distribution (linuma et al., 2012) as in Figure 1. (b) Vertical displacements. Colored contours are observed 2-year vertical displacements. Red and blue arrows represent model-predicted uplift and subsidence. 
with 2 months of observed PE and well water level changes following two $M_{w} 6.5$ earthquakes in basaltic crust of South Iceland (Jónsson et al., 2003). Therefore, it may take only a few tens of days for the shallow poroelastic layer to relax from the earthquake perturbation.

Although PE is a complicated time-dependent process, we use a $3 \mathrm{D}$ elastic model (the same structure as shown in Figure 2a but the material is elastic) to simulate two end-member states to estimate the total effects of PE. The first end-member case represents the immediate response to the earthquake, which is conventionally called the 'undrained' condition. The second scenario represents the state at which the earthquake perturbation on pore fluid pressure reaches an equilibrium state, and transient poroelastic fluid flow has completed. For convenience, we call the second state the 'equilibrium' condition to avoid the confusion of the 'drained' condition that implies no change in pore fluid pressure because of slow loading processes and high permeability. The difference of coseismic model results of these two states thus approximates the total effects of the time-dependent PE that is not modeled in this work.

Following previous studies of poroelastic rebound (e.g., Masterlark and Hughes, 2008; Hughes et al., 2010), the top layers of the subduction slab and the continental crust are assumed to be poroelastic at the time scales considered here. Thicknesses of the poroelastic layer in the slab and continental crust are initially assumed to be 16 and $6 \mathrm{~km}$, respectively. Based on previously published studies (summarized in Additional file 1: Table S1), we assume that Poisson's ratio in the continental poroelastic layer is $v_{u}=0.34$ under undrained conditions (right after the earthquake) and $v=0.25$ under equilibrium conditions. In the oceanic poroelastic layer $v_{u}=0.31$ and $v=0.25$. The shear moduli of the continental and oceanic poroelastic layers are 15 and $20 \mathrm{GPa}$, respectively, for both undrained and equilibrium conditions. The magnitude of the difference in Poisson's ratio between these two conditions is likely an upper bound estimate (Additional file 1: Table S1). This poroelastic model thus represents a maximum estimate of PE contributing to the postseismic deformation. Tests of depth variation of the shear modulus and Poisson's ratio are detailed in Additional file 1: Section 1 and show that allowing poroelastic fluid to flow deeper in the lithosphere does not substantially change the pattern of the predicted surface deformation.

The tendency of fluids to flow from high-pressure areas to low-pressure areas causes uplift above and radial displacements away from the rupture zone as illustrated in Figure 4. PE only in the oceanic crust produces surface displacements mostly in a narrow zone close to the trench (Figure 4b) while PE only in the continental upper plate produces displacements across a broader zone (Figure 4a). Note that the sudden decay of coseismic slip from tens of meters to zero near the trench is probably not physical and the resultant large subsidence in this area may be a model-produced artifact (Figure 4). Nevertheless, most significant deformation in either case takes place in the immediate vicinity of the rupture zone.

Varying the depth extent of the poroelastic layer affects deformation mainly offshore but has little impact for deformation on land (Additional file 1: Figures S4 and S7). PE in the whole continental mantle (e.g., Ogawa and Heki, 2007) has negligible contribution to the surface deformation (Additional file 1: Figure S4d), while $\mathrm{PE}$ in the whole oceanic mantle produces up to $20 \mathrm{~cm}$ subsidence near the landward edge of the rupture zone and more than $10 \mathrm{~cm}$ landward motion near the trench (Additional file 1: Figure S7d). Magnitude and location of the uplift and subsidence produced by PE strongly

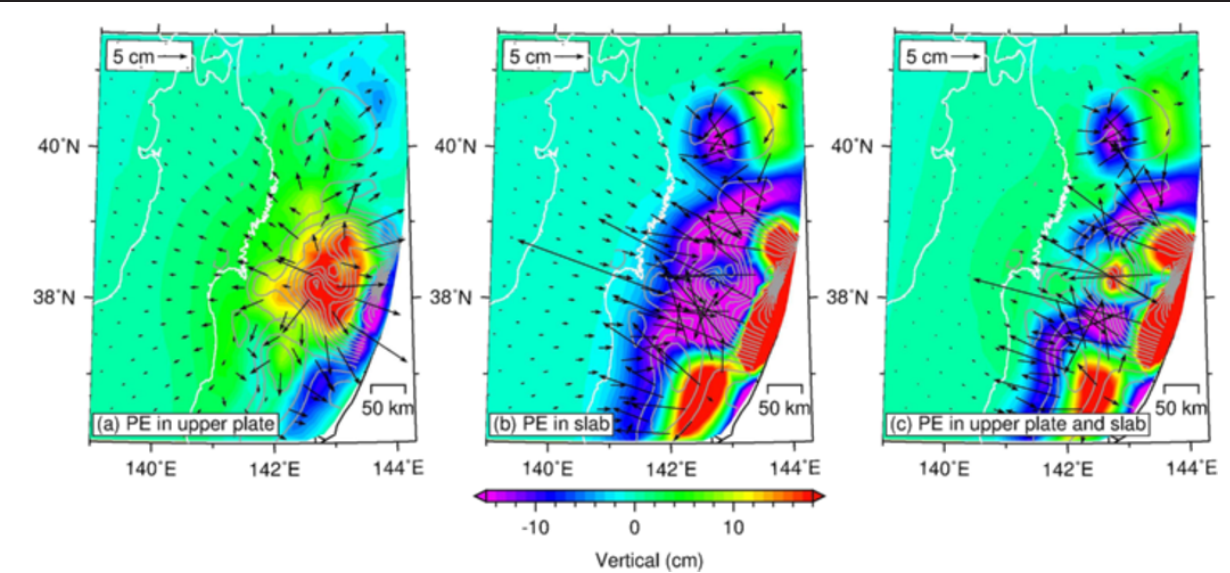

Figure 4 PE in the upper crust. (a) PE only in upper $6 \mathrm{~km}$ of continental crust. (b) PE only in upper $16 \mathrm{~km}$ of the oceanic plate. (c) PE in both continental and oceanic crusts, i.e., the combined effect of (a) and (b). Colored contours and black arrows are vertical and horizontal displacements, respectively. 
depend on source models (Additional file 1: Figure S6). The combined effects of PE in both the upper plate and the slab result in up to approximately $20 \mathrm{~cm}$ uplift in the peak rupture area and up to approximately $15 \mathrm{~cm}$ of subsidence elsewhere offshore (Figure 4c). Re-equilibration of fluid pressures assuming end-member poroelastic properties produces total horizontal displacements of approximately $30 \mathrm{~cm}$ near the offshore rupture area but $<2 \mathrm{~cm}$ on land (Figure 4c).

PE models indicate that PE contributes to the surface deformation mainly offshore, in particular, the vicinity of the rupture area. The up to approximately $20 \mathrm{~cm}$ uplift offshore in PE is opposite to the observed subsidence at GPS-A stations (cyan arrows in Figure 5b). Test models shown in Figure 4 indicate that the observed surface deformation offshore may be caused mainly from PE of the oceanic crust that produces general subsidence except along the seaward edge of the rupture area (Figure $4 \mathrm{~b}$ ). Possible factors affecting the vertical component offshore are as follows. The old, cold, and brittle oceanic lithosphere that was recently normal faulted due to slab bending in the outer rise may be permeable to greater depth. Based on well-located focal mechanisms, Kita et al. (2010) found that a neutral plane separating an upper plane of compressional earthquakes and lower plane of extensional events is located about $22 \mathrm{~km}$ beneath the subduction interface beneath Tohoku. Therefore, PE of a thicker oceanic layer (e.g., the whole $80-\mathrm{km}$ lithosphere in OTC shown in Additional file 1: Figure S7d) would produce more subsidence offshore. The vertical component in PE also strongly depends on the source model as shown in Additional file 1: Figure S6. A more smoothly distributed source model without abrupt peaks would also produce overall subsidence offshore (Additional file 1: Figure S6). In addition to the uncertainty of the source model, the uplift discrepancy offshore may be due to the uniform rock properties assumed in this work. In reality, the forearc prism may be weaker and more permeable than the back arc (e.g., Le Pichon et al., 1993; Hu and Wang, 2008). Because of the limited distribution of measurements offshore, we refrain from further investigation of the lateral heterogeneities of the poroelasticity structure.

\section{Weakened zone beneath volcanic arc}

In this section, we study the effects of a weakened lower crust below the arc on the postseismic deformation. Based on heat flow data (e.g., Cho and Kuwahara, 2013), seismic tomography, and magnetotelluric measurements, Muto (2011) and Muto et al. (2013) estimated the viscosity of the lower crust beneath the arc in NE Japan to be as low as $10^{19} \mathrm{~Pa} \mathrm{~s}$. Based on geodetic observations spanning 2 years following the 2008 Iwate-Miyagi Nairiku earthquake, Ohzono et al. (2012a) preferred a model with a lower crustal viscosity of 2 to $5 \times 10^{18} \mathrm{~Pa}$ s. In a preferred test model of the weak sub-arc crust, we assume that the rheological structure of the weak zone (shown as a light-shaded area in Figure 2) is as follows. Regions shallower than $15 \mathrm{~km}$ are elastic. Between 15 and $25 \mathrm{~km}$, the Maxwell steady-state viscosity $\eta_{\mathrm{M}}$ decreases linearly with a depth from $10^{23}$ to $10^{18} \mathrm{~Pa} \mathrm{~s}$. From 25 to $100 \mathrm{~km}, \eta_{\mathrm{M}}=10^{18} \mathrm{~Pa} \mathrm{~s}$. As long as the bottom depth of the weak zone is greater than the thickness of the continental plate $(40 \mathrm{~km})$, surface deformation is not sensitive to the lower boundary of the weak zone (Additional file 1: Figures S10 and S11). The plan-view

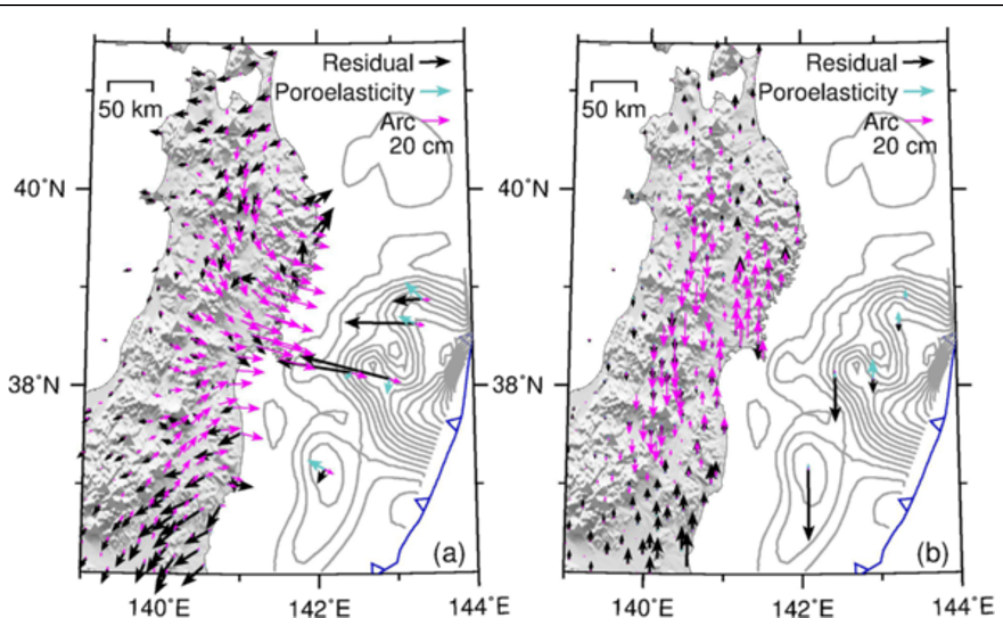

Figure 5 Comparison of REF residuals with test models of poroelasticity and weak sub-arc zone. (a) Horizontal displacements. Black arrows represent the residual of the horizontal displacements shown in Figure 3a (observations minus model-predicted displacements). Cyan arrows represent displacements produced by the test model of the poroelastic rebound shown in Figure 4c. Magenta arrows represent displacements produced by a test model of a weak sub-arc zone shown in Figure 6a. (b) Vertical displacements. Color coding is the same as in (a). 
width of the weak zone is $50 \mathrm{~km}$. The shear modulus and Poisson's ratio of the weak zone are assumed to be $56 \mathrm{GPa}$ and 0.25 , respectively.

Earthquake-induced stresses in the low-viscosity weak zone relax faster than in the surrounding higher-viscosity regions. The resultant shear stress gradient produces diverging surface deformation. We present the model results at 2 years after the earthquake in Figure 6 to demonstrate the effect of this localized relaxation on the surface deformation. Note that effects of the regional relaxation of the upper mantle and afterslip of the fault are all removed such that Figure 6 shows the contribution to the surface deformation only from the weakened sub-arc zone. Horizontal seaward displacements are generally less than $20 \mathrm{~cm}$ in areas seaward of the arc and are less than $5 \mathrm{~cm}$ to the west. For the vertical component, the region to the west of the arc undergoes less than $22 \mathrm{~cm}$ subsidence while areas to the east of the arc undergo less than $18 \mathrm{~cm}$ uplift (Figure 6a). Widths of the subsidence and uplift regions are both nearly $100 \mathrm{~km}$. The wider the planview width of the weak zone is, the larger the magnitude and width of the uplift region. Surface deformation in both horizontal and vertical directions approximately scales with the plan-view width of the weak zone (Additional file 1: Figure S9). An increase in the weakzone viscosity (Additional file 1: Figure S12a) by a factor of 5 produces surface deformation about two times smaller. A further increase by a factor of 2 produces slightly smaller surface displacements (Additional file 1: Figure S12b). The tests thus indicate that surface deformation is not sensitive to the change in the weak-zone viscosity any more if its viscosity is larger than $5 \times 10^{18} \mathrm{~Pa}$.
In the horizontal components, the general seaward motion and counterclockwise rotation in the north (magenta arrows in Figure 5a) is consistent with the misfit between REF and GPS (black arrows in Figure 5a). In the vertical component, the model of the weak sub-arc zone produces uplift along the eastern coast and subsidence farther inland (Figure $5 \mathrm{~b}$ ), a pattern similar to that of the GPS observations as shown in Figure 1b. We present displacements along a surface profile to further illustrate how accounting for the weak sub-arc zone may help eliminate systematic misfits in the viscoelastic model as shown in Figure 5. The surface line shown as a thick red line in Figure 6a starts at the trench near latitude $38^{\circ} \mathrm{N}$ and extends inland in the direction of the subduction of the Pacific plate. We use the difference between the GPS observations and REF predicted displacements (observation minus model) to approximate the postseismic deformation due to processes other than the mantle relaxation and afterslip of the fault. Despite the scarcity of observations along this profile, modelpredicted displacements in both horizontal and vertical directions agree well with the first-order pattern of the residuals (Figure 6b,c,d). A denser geodetic network (e.g., Ohzono et al., 2012b) may help further constrain the location and properties of the weak region beneath the arc.

It has been observed that the coastal area undergoes long-term uplift (e.g., Antonioli et al., 2009; RamíRezHerrera et al., 2011). However, interseismic re-locking of the megathrust and coseismic deformation of subduction zone earthquakes all indicate subsidence in the coast area. Total postseismic deformation in an earthquake
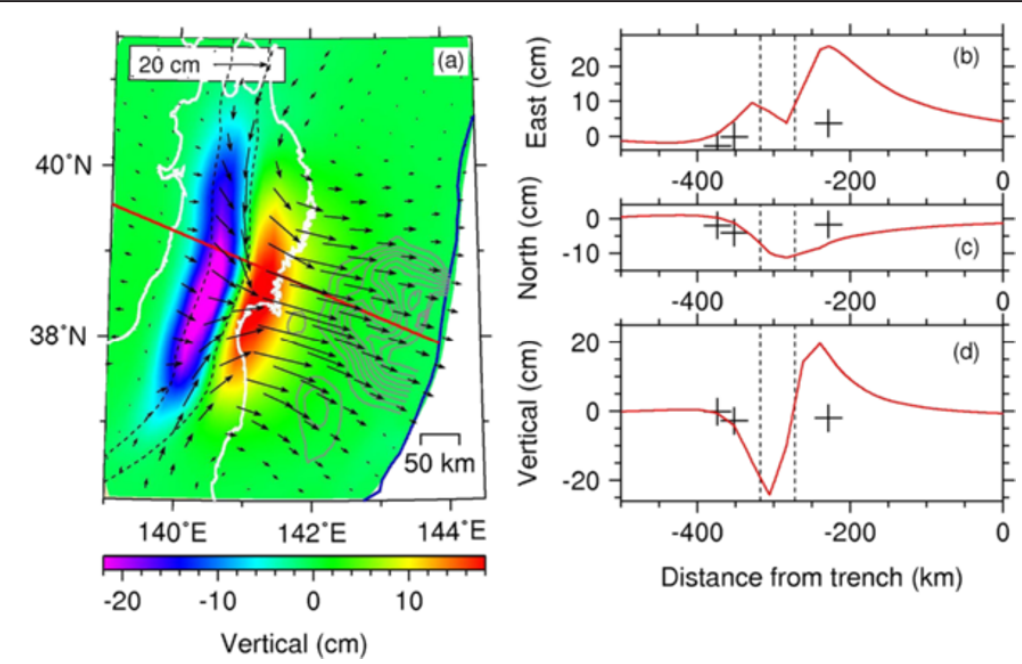

Figure 6 Effects of the weakened zone beneath the volcanic arc on postseismic displacements. Model results are presented at 2 years after the earthquake. (a) Surface displacements. Black arrows and color contours are horizontal and vertical displacements, respectively. (b-d) East, North, and vertical displacement components along a surface line shown as a thick red line in (a) are plotted in (b), (c), and (d), respectively. Red lines denote model-predicted displacements. Black cross represents the residual of GPS observations and displacements produced by the reference VE model as shown in Figure 3. Thin dashed lines outline the location of the modeled weak sub-arc zone. 
cycle is subsidence in the coast area but about one order of magnitude lower than the interseismic locking (results not shown). The intriguing vertical deformation due to the weak sub-arc zone (Figure 6) may yield information on the long-term terrestrial deformation.

\section{Conclusions}

We have constructed finite element models to study the effects of poroelastic rebound on the postseismic deformation following the 2011 Tohoku earthquake. Our tests indicate that the PE contribution to surface deformation is mainly limited to the vicinity of the rupture area. The reference PE model produces up to approximately $20 \mathrm{~cm}$ uplift near the zone of peak slip of the rupture area and up to approximately $15 \mathrm{~cm}$ subsidence elsewhere offshore. On land, PE produces 0 to $5 \mathrm{~cm}$ uplift. Horizontal displacements are less than $2 \mathrm{~cm}$ on land and up to approximately $30 \mathrm{~cm}$ offshore. Observed general subsidence at GPS-A stations offshore indicates that contributions to the surface deformation may be mainly due to PE of the oceanic crust. Offshore surface deformation from PE strongly depends on the source model. A smoothly distributed source model without abrupt peakslip areas would produce overall subsidence offshore. Fit to postseismic GPS measurements on land and offshore in the horizontal components may be improved by accounting for the PE contribution in the model incorporating mantle relaxation and afterslip of the fault.

We have also studied the effects of a weakened zone in the lower crust and upper mantle beneath the volcanic arc of NE Japan. Viscosities of the lower crust in the weak zone are several orders of magnitude lower than the surrounding areas. For a sub-arc viscosity of $10^{18} \mathrm{~Pa} \mathrm{~s}$, model-predicted surface motions on land over 2 years after the earthquake are generally less than approximately $20 \mathrm{~cm}$ seaward in the horizontal direction, up to $22 \mathrm{~cm}$ subsidence west of the arc, and up to $18 \mathrm{~cm}$ uplift to the east. Accounting for the sub-arc weak zone helps eliminate the systematic misfit in the reference viscoelastic model of upper mantle relaxation and afterslip of the megathrust.

\section{Additional file}

Additional file 1: Supplementary material. Presented in the supplementary material are the method of estimating postseismic displacements, test models of poroelasticity and weak sub-arc zone, and data of estimated first 2-year cumulative postseismic GPS displacements.

\section{Competing interests}

The authors declare that they have no competing interests.

\section{Authors' contributions}

$\mathrm{YH}$ and RB participated in the design of the study. YH carried out numerical tests and drafted the manuscript. PB provided GPS data. YH and JF participated in post-processing GPS time series. KW provided assistance on finite element code. All authors participated in proofreading of the manuscript. All authors read and approved the final manuscript.

\section{Acknowledgements}

We are thankful for the computing facility provided by Bruce Buffett and thankful for the publicly available GPS time series of GEONET by GSI. We also appreciate discussions with Fred Pollitz, Naoki Uchida, Mariko Sato, and Stephen Kirby. We thank two anonymous reviewers for the helpful comments that greatly improved the manuscript. This work was funded by NSF award EAR-1246850 and benefitted from support by the Miller Institute for Basic Research in Science. Berkeley Seismological Laboratory contribution 14-16.

\section{Author details}

'Berkeley Seismological Laboratory and Department of Earth and Planetary Science, University of California Berkeley, 307 McCone Hall, Berkeley, CA 94720, USA. ${ }^{2}$ University of Alaska Fairbanks, Fairbanks, AK 99775, USA. ${ }^{3}$ Earth

Observatory of Singapore, Nanyang Technological University, Singapore 639798, Singapore. ${ }^{4}$ Pacific Geoscience Centre, Geological Survey of Canada, Sidney, BC V8L 4B2, Canada.

Received: 11 March 2014 Accepted: 18 August 2014

Published: 2 September 2014

\section{References}

Altamimi Z, Collilieux X, Métivier L (2011) ITRF2008: an improved solution of the international terrestrial reference frame. J Geod 85:457-473, doi: 10.1007/ s00190-011-0444-4

Antonioli F, Ferranti L, Fontana A, Amorosi A, Bondesan A, Braitenberg C, Dutton A, Fontolan G, Furlani S, Lambeck K, Mastronuzzi G, Monaco C, Spada G, Stocchi P (2009) Holocene relative sea-level changes and vertical movements along the Italian and Istrian coastlines. Quaternary Int 206:102-133, doi: 10.1016/j.quaint.2008.11.008

Apel E, Bürgmann R, Steblov G, Vasilenko N, King R, Prytkov A (2006) Active tectonics of northeast Asia: using GPS velocities and block modeling to test independent Okhotsk plate motion. Geophys Res Lett 33: doi: 10.1029/ 2006GL026077

Bird P (2003) An updated digital model of plate boundaries. Geochem Geophys Geosyst 4(3):1027, doi: 10.1029/2001GC000252

Bürgmann R, Dresen G (2008) Rheology of the lower crust and upper mantle: evidence from rock mechanics, geodesy, and field observations. Annu Rev Earth Planet Sci 36:531-567, doi: 10.1146/annurev.earth.36.031207.124326

Cho I, Kuwahara Y (2013) Constraints on the three-dimensional thermal structure of the lower crust in the Japanese Islands. Earth Planets Space 65:855-861, doi: 10.5047/eps.2013.01.005

Diao F, Xiong X, Wang R, Zheng Y, Walter TR, Weng H, Li J (2014) Overlapping post-seismic deformation processes: afterslip and viscoelastic relaxation following the 2011 Mw 9.0 Tohoku (Japan) earthquake. Geophys J Int 196:218-229, doi: 10.1093/gji/ggt376

Engdahl ER, van der Hilst R, Buland R (1998) Global teleseismic earthquake relocation with improved travel times and procedures for depth determination. Bull Seismo Soc Am 88(3):722-743

Japan Coast Guard (2012) Seafloor movements obtained by seafloor geodetic observations after the 2011 off the Pacific coast of Tohoku earthquake. Rep Coord Comm Earthq Predict 88:150-154 (In Japanese)

Japan Coast Guard and Tohoku University (2013) Seafloor movements observed by seafloor geodetic observations after the 2011 off the Pacific coast of Tohoku Earthquake. Rep Coord Comm Earthq Predict 90:3-4

Hu Y, Wang K (2008) Coseismic strengthening of the shallow portion of the subduction fault and its effects on wedge taper. J Geophys Res 113, B12411, doi: 10.1029/2008JB005724

Hu Y, Wang K (2012) Spherical-Earth finite element model of short-term postseismic deformation following the 2004 Sumatra earthquake. J Geophys Res 117 (B5):B05404, doi: 10.1029/2012JB009153

Hu Y, Wang K, He J, Klotz J, Khazaradze G (2004) Three-dimensional viscoelastic finite element model for post-seismic deformation of the great 1960 Chile earthquake. J Geophys Res 109, B12403, doi: 10.1029/2004JB003163

Hughes KLH, Masterlark T, Mooney WD (2010) Poroelastic stress-triggering of the 2005 M8.7 Nias earthquake by the 2004 M9.2 Sumatra-Andaman earthquake. Earth Planet Sci Lett 293(3-4):289-299, doi: 10.1016/j.epsl.2010.02.043 
linuma T, Hino R, Kido M, Inazu D, Osada Y, Ito Y, Ohzono M, Tsushima H, Suzuki S, Fujimoto H, Miura S (2012) Coseismic slip distribution of the 2011 off the Pacific coast of Tohoku Earthquake (M9.0) refined by means of seafloor geodetic data. J Geophys Res 117:B07409, doi:10.1029/2012JB009186

Johnson KM, Fukuda J, Segall P (2012) Challenging the rate-state asperity model: afterslip following the 2011 M9 Tohoku-oki, Japan, earthquake. Geophys Res Lett 39:L20302, doi: 10.1029/2012GL052901

Jónsson S, Segall P, Pedersen R, Björnsson G (2003) Post-earthquake ground movements correlated to pore-pressure transients. Nature 424:179-183, doi: 10.1038/nature01776

Kido M, Fujimoto H, Osada Y, Ohta Y, Tadokoro K, Watanabe T, Nagai S, Yasuda K, Okuda T, Yamamoto J (2013) Precision evaluation for intensive GPS acoustic measurements along Japan trench, Abstract G11B-0913 presented at 2013 Fall Meeting. AGU, San Francisco, CA, USA

Kita S, Okada T, Hasegawa A, Nakajima J, Matsuzawa T (2010) Anomalous deepening of a seismic belt in the upper-plane of the double seismic zone in the Pacific slab. Earth Planet Sci Lett 290(3-4):415-426, doi: 10.1016/j. epsl.2009.12.038

Le Pichon X, Henry P, Lallemant S (1993) Accretion and erosion in subduction zones: the role of fluids. Annu Rev Earth Planet Sci 21:307-331

Lin YN, Sladen A, Ortega-Culaciati F, Simons M, Avouac J-P, Fielding EJ, Brooks BA, Bevis M, Genrich1 J, Rietbrock A, Vigny C, Smalley R, Socquet A (2013) Coseismic and postseismic slip associated with the 2010 Maule earthquake, Chile: characterizing the Arauco peninsula barrier effect. J Geophys Res Solid Earth 118:3142-3159, doi:10.1002/jgrb.50207

Manning CE (2004) The chemistry of subduction-zone fluids. Earth Planet Sci Lett 223(1-2):1-16, doi: 10.1016/j.epsl.2004.04.030

Manning CE, Ingebritsen SE (1999) Permeability of the continental crust: implications of geothermal data and metamorphic systems. Rev Geophys 37 (1):127-150, doi: 10.1029/1998RG900002

Masterlark T (2003) Finite element model predictions of static deformation from dislocation sources in a subduction zone: sensitivities to homogeneous, isotropic, Poisson-solid, and half-space assumptions. J Geophys Res 108: doi: 10.1029/2002JB002296

Masterlark T, Hughes KLH (2008) Next generation of deformation models for the 2004 M9 Sumatra-Andaman earthquake. Geophys Res Lett 35:L19310, doi: 10.1029/2008GL035198

McCaffrey R, King RW, Payne SJ, Lancaster M (2013) Active tectonics of northwestern U.S. inferred from GPS-derived surface velocities. J Geophys Res Solid Earth 118:709-723, doi: 10.1029/2012JB009473

Melosh HJ, Raefsky A (1981) A simple and efficient method for introducing faults into finite element computations. Bull Seismol Soc Am 71:1391-1400

Miyazaki S, Hatanaka Y, Nakamura H (1998) About continuous GPS monitoring system of GSI, in Kishyo Kenkyu, vol 192. Meteorological Society of Japan, Japanese, pp 105-131

Muto J (2011) Rheological structure of northeastern Japan lithosphere based on geophysical observations and rock mechanics. Tectonophysics 503:201-206, doi: 10.1016/j.tecto.2011.03.002

Muto J, Shibazaki B, Ito Y, linuma T, Ohzono M, Matsumoto T, Okada T (2013) Two-dimensional viscosity structure of the northeastern Japan islands arc-trench system. Geophys Res Lett 40:4604-4608, doi: 10.1002/grl.50906

Nakajima J, Hasegawa A (2006) Anomalous low-velocity zone and linear alignment of seismicity along it in the subducted Pacific slab beneath Kanto, Japan: reactivation of subducted fracture zone? Geophys Res Lett 33:L16309, doi: 10.1029/2006GL 026773

Nur A, Walder J (1990) Time-dependent hydraulics of the earth's crust. In: National Research Council (ed) The role of fluids in crustal processes. National Academy Press, Washington, DC, pp 113-127

Ogawa R, Heki K (2007) Slow postseismic recovery of geoid depression formed by the 2004 Sumatra-Andaman earthquake by mantle water diffusion. Geophys Res Lett 34:L06313, doi: 10.1029/2007GL029340

Ohzono M, Ohta Y, linuma T, Miura S, Muto J (2012a) Geodetic evidence of viscoelastic relaxation after the 2008 Iwate-Miyagi Nairiku earthquake. Earth Planets Space 64(9):759-764, doi: 10.5047/eps.2012.04.001

Ohzono M, Yabe Y, linuma T, Ohta Y, Miura S, Tachibana K, Sato T, Demachi T (2012b) Strain anomalies induced by the 2011 Tohoku earthquake (Mw 9.0) as observed by a dense GPS network in northeastern Japan. Earth Planets Space 64:1231-1238, doi: 10.5047/eps.2012.05.015

Ozawa S, Nishimura T, Munekane H, Suito H, Kobayashi T, Tobita M, Imakiire T (2012) Preceding, coseismic, and postseismic slips of the 2011 Tohoku earthquake, Japan. J Geophys Res 117:B07404, doi: 10.1029/2011JB009120
Peltzer G, Rosen P, Rogez F, Hudnut K (1996) Postseismic rebound in fault step-overs caused by pore fluid flow. Science 273:1202-1204

Peltzer G, Rosen P, Rogez F, Hudnut K (1998) Poroelastic rebound along the Landers 1992 earthquake surface rupture. J Geophys Res 103(B12):30131-30145, doi: 10.1029/98JB02302

Pollitz FF, Banerjee P, Grijalva K, Nagarajan B, Bürgmann RB (2008) Effect of 3-D viscoelastic structure on post-seismic relaxation from the $2004 \mathrm{M}=9.2$ Sumatra earthquake. Geophys J Int 173(1):189-204, doi: 10.1111/j.1365246X.2007.03666.X

Pollitz FF, Bürgmann R, Banerjee P (2011) Geodetic slip model of the 2011 M9.0 Tohoku earthquake. Geophys Res Lett 38:L00G08, doi:10.1029/2011GL048632

RamíRez-Herrera MT, Kostoglodov V, Urrutia-Fucugauchi J (2011) Overview of recent coastal tectonic deformation in the Mexican subduction zone. Pure Appl Geophys 168(8-9):1415-1433, doi: 10.1007/s00024-010-0205-y

Saffer D, Bekins B (1999) Fluid budgets at convergent plate margins: implications for the extent and duration of fault-zone dilation. Geology 27:1095-1098

Sato M, Fujita M, Matsumoto Y, Ishikawa T, Saito H, Mochizuki M, Asada A (2013) Interplate coupling off northeastern Japan before the 2011 Tohoku-oki earthquake, inferred from seafloor geodetic data. J Geophys Res 118(7): doi: 10.1002/jgrb.50275

Savage JC (1983) A dislocation model of strain accumulation and release at a subduction zone. J Geophys Res 88:4984-4996

Sella GF, Dixon TH, Mao A (2002) REVEL: a model for recent plate velocities from space geodesy. J Geophys Res 107:2081, doi: 10.1029/2000JB000033

Suito H, Freymueller JT (2009) A viscoelastic and afterslip postseismic deformation model for the 1964 Alaska earthquake. J Geophys Res 114: B11404, doi: 10.1029/2008JB005954

Uchida N, Matsuzawa T (2013) Pre-and postseismic slow slip surrounding the 2011 Tohoku-oki earthquake rupture, Earth Planet. Sci Lett 374:81-91, doi: 10.1016/j.epsl.2013.05.021

Van Keken PE, Kiefer B, Peacock SM (2002) High-resolution models of subduction zones: implications for mineral dehydration reactions and the transport of water into the deep mantle. Geochem Geophys Geosyst 3(10):1056 doi: 10.1029/2001GC000256

Wang K, Wells RE, Mazzotti S, Hyndman RD, Sagiya T (2003) A revised dislocation model of interseismic deformation of the Cascadia subduction zone. J Geophys Res 108(B1): doi: 10.1029/2001JB001227

Wang K, Hu Y, Bevis M, Kendrick E, Smalley R Jr, Vargas RB, Lauría E (2007) Crustal motion in the zone of the 1960 Chile earthquake: detangling earthquake-cycle deformation and forearc-sliver translation. Geochem Geophys Geosyst 8(10): Q10010, doi: 10.1029/2007GC001721

Wang K, Hu Y, He J (2012) Deformation cycles of subduction earthquakes in a viscoelastic Earth. Nature 484:327-332, doi: 10.1038/nature11032

Watanabe S, Sato M, Fujita M, Ishikawa T, Yokota Y, Ujihara N, Asada A (2014) Evidence of viscoelastic deformation following the 2011 Tohoku-Oki earthquake revealed from seafloor geodetic observation. Geophys Res Lett 41: doi:10.1002/2014GL061134

Zhao D, Wang Z, Umino N, Hasegawa A (2009) Mapping the mantle wedge and interplate thrust zone of the northeast Japan arc. Tectonophysics 467:89-106

\section{doi:10.1186/1880-5981-66-106}

Cite this article as: Hu et al:: Contributions of poroelastic rebound and a weak volcanic arc to the postseismic deformation of the 2011 Tohoku earthquake. Earth, Planets and Space 2014 66:106.

\section{Submit your manuscript to a SpringerOpen ${ }^{\mathcal{D}}$ journal and benefit from:}

- Convenient online submission

Rigorous peer review

- Immediate publication on acceptance

- Open access: articles freely available online

- High visibility within the field

- Retaining the copyright to your article

Submit your next manuscript at $>$ springeropen.com 